\title{
A question of trust
}

\author{
It isn't enough to explain the facts of climate change very, very clearly. Building public trust requires \\ researchers to change their practices.
}

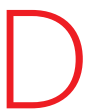
espite the scandals over leaked e-mails at the University of East Anglia, UK, and flawed data in the most recent assessment from the Intergovernmental Panel on Climate Change (IPCC), the scientific evidence for global warming remains strong. The question, then, is to what extent have the controversies eroded the public's trust in climate science or, worse, in the scientists themselves?

There has undoubtedly been some slippage. But a closer look at the data across multiple polls shows that, broadly speaking, the public trusts scientists, believes in global warming and wants governments to do something about it (see page 24). The public seems to have done what the mainstream media could not: it has kept the scandals in perspective. The scathing verbal attacks on climate science and scientists are actually coming from a relative handful of critics, and they do not reflect a broader resurgence of scepticism.

Yet few climate scientists are likely to take satisfaction in this news. For them, the real measure of public trust is the level of political engagement on global warming: if people truly believe the science, then why have so few of them demanded action of their governments? Why is the world still at loggerheads over climate change?

The problem is that people assess information from any number of sources, not just scientists. And people - politicians included make decisions on the basis of self-interest and their own hopes, fears and values, which will not necessarily match what many researchers deem self-evident.

The scientific community must recognize that the issues surrounding climate change resonate with the public and politicians on many different levels. Facts do matter. Scientists must continue to engage the public in plain language whenever possible, laying out the evidence for climate change in a clear and compelling way. And they must provide policy-makers in both the public and private sectors with accurate, credible and timely information (see page 30 ). But, given the complexity of that evidence, and the many uncertainties that remain, scientists will be only as persuasive as they are trusted which means that preserving and cultivating the public's trust must be the scientific community's top priority.

As the recent controversies have made abundantly clear, individual researchers must learn to see themselves as public figures and honest brokers. In particular, they must recognize that questionable data management and improper restrictions on the release of data - or on the details of how those data were processed - undermine both public confidence and scientific integrity by impeding "Researchers must learn to see themselves as public figures and honest brokers." independent expert assessment.

More generally, scientists, institutions and funding agencies must increase transparency wherever possible. When engaging the public, the kind of uncertainties and internal debates that scientists struggle with on a daily basis should be played up, not down (see page 31). Likewise, neither the IPCC nor national governments should endorse regional studies that overstate scientists' ability to forecast the local effects of climate change on short timescales.

Finally, scientists must steer clear of hype and rein in exaggerations about the threat of global warming. Those who seek to sow doubt about the solid and widespread evidence for global warming must be countered with facts as a matter of course. But legitimate fears and scientific scepticism must be welcomed into the discussion.

The science isn't complete and never will be, but it is sufficiently robust that broad conclusions cannot be undermined by questions about any given datum point. From this perspective, the fact that climate scientists can't predict exactly how bad the impacts might be could well be the best argument for action.

\section{Order from chaos}

\section{Much tighter regulations are needed to reap the full benefits of stem-cell treatments.}

S tem-cell therapy is nothing new. The transplantation of bone marrow to treat blood cancers such as leukaemia and lymphoma has existed for decades: the therapy works because marrow contains blood-forming stem cells that can replace the cells being destroyed.

But the stem cells involved in such treatments simply continue to perform their natural function. What is new - and concerning is a trend towards transplants in which the stem cells are expected to behave in different ways, even though there is little empirical evidence to suggest that they can do so. The perils of that approach were highlighted last week, when researchers reported the discovery of strange lumps of cells in the kidney of a woman who had undergone stem-cell treatment in Thailand (see Nature 465, 997; 2010). In another case last year, an Israeli boy developed tumours after being injected several times in a Moscow hospital with what was later determined to be a slurry of mixed fetal tissues.

There are at present estimated to be more than 200 clinics worldwide - including more than 100 in China alone - offering what are often unproven stem-cell treatments for scores of disorders including spinal-cord injury, amyotrophic lateral sclerosis and multiple sclerosis (see Nature 459, 146-147; 2009). The potential profits are huge: there is an abundance of patients desperate for miracle cures, and one stem-cell treatment can bring in tens of thousands of US dollars.

Practitioners at these clinics claim that their treatments are safe and effective. But they typically base those claims on little more than 